\title{
Qualidade de Vida no Trabalho: um Estudo Sobre a Percepção dos Operadores de Telemarketing de uma Empresa de Call Center Situada na Cidade de Imperatriz
}

\section{Quality of Life at Work: a Study on the Telemarketing Operators Perception of a Call Center Company Situated in the City of Imperatriz}

\author{
Eduardo dos Reis Silva*a; Romario Ferreira Santos ${ }^{a}$; Thiago Sousa Silva ${ }^{a}$
}

aniversidade Estadual da Região Tocantina do Maranhão, Curso de Administração. MA, Brasil.

*E-mail: eduardo16rs@hotmail.com

\begin{abstract}
Resumo
A Qualidade de Vida no Trabalho (QVT) tem um papel importante no desempenho de atividades voltadas para satisfação e bem-estar dos funcionários, trazendo benefícios esperados por parte do empregado e do empregador. As organizações que pretendem impulsionar a produtividade e melhorar a eficiência de entrega de seus serviços, precisam investir em seu capital humano, afinal, são estes os responsáveis por trazerem resultados para a corporação. O presente artigo tem como objetivo analisar os aspectos que contribuem para satisfação ou insatisfação no ambiente de trabalho dos operadores de telemarketing, em uma empresa de call center, responsável por realizar cobranças, localizada na cidade de Imperatriz/MA, neste caso, analisando questões relativas à segurança e saúde no trabalho, interação social, oportunidade de crescimento, entre outras. Quanto aos métodos, a pesquisa é de caráter exploratório, sendo um estudo de caso em um setor específico da organização, call center, no qual foram utilizados questionários fechados com treze questões de múltipla escolha, para identificar a percepção dos colaboradores quanto à proposta de QVT adotada. Os resultados evidenciam que a maioria dos operadores se sentem satisfeitos com questões relacionadas à QVT na empresa pesquisada, todavia, foram identificadas situações nas quais a corporação deve trabalhar para melhorar ainda mais a satisfação dos colaboradores.
\end{abstract}

Palavras-chave: Qualidade de Vida no Trabalho. Call Center. Operador de Telemarketing. Satisfação.

\begin{abstract}
The Quality of Life at Work (QWL) has an important role in the performance of activities aimed at employee satisfaction and well-being, bringing expected benefits from the employee and the employer. Organizations that intend to boost productivity and improve the delivery efficiency of their services, need to invest in their human capital, after all, these are the ones responsible for bringing results to the corporation. This article aims to analyze the aspects that contribute to satisfaction or dissatisfaction in the work environment of telemarketing operators, in a call center company, responsible for making collections, located in the city of Imperatriz / MA, in this case, analyzing issues related to safety and health at work, social interaction, growth opportunity, among others. As for the methods, the research is exploratory, being a case study in a specific sector of the organization, call center, where closed questionnaires with 13 multiple choice questions were used to identify the collaborators perception regarding the proposal of the adopted QWL. The results show that the majority of operators feel satisfied with issues related to QWL in the researched company, however, situations that the corporation must work to further improve employee satisfaction were identified.
\end{abstract}

Key words: Quality of Life at Work. Call Center. Telemarketing Operator. Satisfaction.

\section{Introdução}

É crescente o grau de competitividade entre as empresas em função da globalização e a tecnologia. A busca pela qualidade é real e vista em todo e qualquer tipo de organização que pretende obter uma boa colocação no mercado, em razão das exigências e necessidades que o consumidor determina a cada dia. Para tanto, as áreas organizacionais necessitam desempenhar atividades coordenadas por meio do suporte de programas relacionados à eficiência e qualidade dos seus serviços, para que assim possa seguir os padrões exigidos pelo seu cliente final.

Visando o interesse e preocupação das organizações quanto à respectiva produtividade e motivação dos seus colaboradores no ambiente organizacional, a (QVT) é um tema de extrema relevância no contexto atual das empresas, procurando regular e criar políticas que proporcionem um ambiente saudável e adequado ao profissional.

Segundo Fernandes (1996), a qualidade de produtos e serviços está relacionada com a qualidade de vida no trabalho. Dessa forma, quando se fala em QVT se procura criar e manter um ambiente com condições de higiene, de segurança e, também, condições sociais e psicológicas para o funcionário, promovendo por parte do empregador, meios que incentivem e motivem seus colaboradores.

A atividade de operador de telemarketing é a função que se incorpora ao setor de call center das empresas que trabalham como foco no teleatedimento direcionado ao seu público-alvo, através do relacionamento interpessoal por meio do telefone. 
Existem várias categorias em que o operador tem como área de atuação, por exemplo: vendas de produtos, Serviços de Atendimento ao Consumidor (SAC), serviço de cobrança e inadimplência, entre outros.

A presente pesquisa é direcionada a uma empresa de call center que tem como propósito a prestação de serviço de cobrança, na qual se incorpora um setor de call center instalada na cidade de Imperatriz-MA, que tem como serventia a gestão de clientes de instituições parceiras, principalmente, escolas e Universidades particulares. $\mathrm{O}$ atendimento acontece por meio de uma equipe de profissionais - operadores de telemarketing - que recebem e fazem ligações diárias para clientes na realização de procedimentos de cobrança e inadimplência, em que todos são treinados e capacitados para atuarem nessa área, necessitando de bastante atenção e dedicação por parte de cada um, que lida com situações adversas e pressões diárias.

Busca-se investigar aspectos relacionados a QVT como: motivação, integração social na organização, segurança e saúde no trabalho, entre outras que podem contribuir para satisfação com o trabalho esperado pelo empregado, assim incorporando uma conjunta ideia de eficiência e produtividade esperada por parte do empregador.

Visando interesse de investigar sobre o tema QVT no ambiente organizacional destes profissionais, a pesquisa tem como propósito levantar os principais aspectos que colaboram para satisfação ou insatisfação, e que afetam em seu processo de atividade e desempenho destes trabalhadores.

Frente ao apresentado, o presente estudo tem como objetivo geral, analisar a percepção que os operadores de telemarketing têm sobre a qualidade de vida no trabalho e responder a seguinte problemática: qual percepção os operadores de telemarketing de uma empresa de call center têm da Qualidade de Vida no trabalho e sua influência na produtividade?

\section{Material e Métodos}

A pesquisa apresentada tem caráter descritivo, porque visa descrever, identificar e caracterizar os níveis de QVT no ambiente organizacional dos operadores de telemarketing de uma empresa de gestão de cobrança, em que se incorpora um setor de call center. Segundo Gil (2008, p.28): "as pesquisas deste tipo têm como objetivo primordial a descrição das características de determinada população ou fenômeno, ou o estabelecimento de relações entre variáveis". Ainda se utilizará da pesquisa bibliográfica, em que se faz uso de materiais já elaborados, como livros, artigos científicos, revistas e documentos eletrônicos na busca e alocação de conhecimento sobre qualidade de vida no trabalho.

Contudo, a pesquisa se trata de um estudo de caso de um setor específico da organização, que é próprio setor de call center, no qual se encontram em torno de vinte e cinco operadores que contém todo Universo amostral a ser estudado, em que foi feita a pesquisa com dez operadores de diferentes turnos e com mais de um ano de empresa. De acordo com Yin (2001, p. 32), estudo de caso é "uma investigação empírica que investiga um fenômeno contemporâneo dentro do seu contexto da vida real, especialmente quando os limites entre fenômeno e o contexto não estão claramente definidos".

Quanto ao método se utilizou o de caráter quantitativo, em que foram utilizados questionários com treze perguntas, de forma fechada, baseadas no modelo de Walton (1975). Para Richardson (2011), “em sentido genérico, método em pesquisa significa a escolha de procedimentos sistemáticos para a descrição e explicação de fenômenos".

\section{Resultados e Discussão}

\subsection{Qualidade de Vida no Trabalho - QVT: Conceitos}

O tema qualidade de vida no trabalho ganhou atenção e abrangência no ambiente corporativo, preocupados com a organização do trabalho e produtividade dentro das empresas, a QVT se tornou um mecanismo de valorização e satisfação da condição humana no trabalho.

Os conceitos de qualidade de vida no trabalho englobam melhores condições nos aspectos: saúde, físico, emocional e social. Incluem-se nesse aspectos o amor, a realização pessoal, o ambiente, a saúde, o lazer, a educação, entre outros (RIBEIRO; SANTANA, 2015).

As pessoas passam boa parte de suas vidas nas organizações, o qual precisa e necessita de um ambiente seguro e saudável, e que realizem incentivos à promoção da saúde e qualidade no trabalho, para realização pessoal. Dessa maneira, a presença e a participação da organização para o contínuo desenvolvimento do bem-estar e comprometimento do funcionário com as metas da empresa é de suma importância.

Há diferentes definições sobre a relação de qualidade de vida nas organizações, que influem ou não para valorização do capital humano, conforme Nascimento (2016, p.10): “a qualidade de vida no trabalho pode ser definida pela busca do equilíbrio psicológico, físico e social onde são respeitadas as necessidades e limitações do ser humano resultando em um crescimento pessoal e profissional [...]".

Para Martins (2002), alguns fatores são importantes a se considerar em relação à qualidade de vida no trabalho, que são: as condições do trabalho, da satisfação, do salário, de relações familiares, de disposição, de estado de saúde, de longevidade, de lazer, de prazer, de hereditariedade, de estilo de vida e até espiritualidade, em que todos os fatores são pontos que devem ser considerados para sua obtenção e manutenção.

A presença e a participação da organização para o contínuo desenvolvimento do bem-estar e comprometimento do funcionário com as metas da empresa é de suma importância. No entanto, o empenho e a motivação a que o colaborador deveria estar com a empresa, por sua vez, não dependem só da organização, mas depende intrinsicamente das características pessoais de cada indivíduo, ou seja, aspectos subjetivos, e quais fatores os motivam. 
A globalização, que transformou a sociedade atual, ocasionou um ritmo acelerado de produção e tecnologia. Dessa forma, exigindo mais da mão de obra de profissionais para fornecer serviços em tempos ágeis e com maior habilidade. Para tanto, trouxe consequências relacionadas com a qualidade de vida dos brasileiros (ROCHA; FERNANDES, 2007).

Nesse contexto, o setor de prestação de serviço não é diferente, com demanda maior em função do crescimento de mercados, este setor precisa de profissionais especializados e motivados. Para Chiavenato (2004), o crescimento proporciona a elevação dos recursos necessários para uma empresa, em seguida, aumenta o número de pessoas, com isso, cabe a organização aplicar suas competências fundamentais à manutenção e competitividade do negócio, investindo em seu diferencial competitivo: as pessoas.

A devida gestão de QVT nas organizações valoriza seus funcionários como forma de agregar e contribuir para o desenvolvimento pessoal e organizacional. Dessa forma, modificando e implantando melhorias nos processos, além de melhorar a forma de direcionamento do trabalho.

A introdução e a divulgação do Programa de QVT na empresa pode e deve estar alinhado com as metas e objetivos da organização, como forma de despertar o interesse e conhecimento do funcionário.

Em sua essência, as ações de QVT são definidas como um movimento que busca o envolvimento participativo e amigável entre empregados e organização, "o qual seria capaz de se traduzir em alto nível de satisfação e motivação, em efetividade organizacional e na preservação da saúde do sistema" (SANT'ANNA; KILIMNIK; MORARES, 2011, p.11).

A compreensão e a participação de todos os colaboradores é de extrema importância durante o processo de melhorias e implantação de sistemas ligados à qualidade nos processos e pessoas. Dessa forma, melhorando não só aspectos voltados para a saúde do funcionário, mas o grau de produtividade e eficiência nos serviços prestados pelo colaborador.

\subsection{Fatores relacionados à Qualidade de Vida no Trabalho - QVT}

Existe inúmeros fatores que afetam o ambiente de trabalho tornando-o desagradável. Conforme Barretos (2008), o principal fator que pode provocar o estresse é a sobrecarga de trabalho, ou seja, o acúmulo de tarefas, a falta de organização e a necessidade de distribuir as tarefas e funções (delegação).

Sabendo que o estresse colabora para insatisfação e, consequentemente, compromete o desempenho do colaborador no ambiente de trabalho, a empresa tem o compromisso de identificar fatores que levam ao estresse, seja esse por carga intensa de trabalho, falta de planejamento de carreira, comunicação interna falha ou propriamente a fatores externos (fora do ambiente de trabalho). E para que haja uma devida atenção aos fatores de promoção à saúde e bem-estar do colaborador, é imprescindível que exista uma política de recursos humanos eficiente e competente na organização, para promover métodos e políticas de cargos e salários, avaliação de desempenho, e um bom clima organizacional, a qual contribui para o bem-estar do trabalhador. A qualidade de vida no trabalho assimila duas posições: a reivindicação dos funcionários quanto ao bem-estar e satisfação no trabalho e o interesse das organizações quanto ao seu efeito sobre a produtividade e a qualidade (CHIAVENATO, 2004).

A visão de um ambiente salubre e com condições que favoreçam motivação e crescimento profissional é almejado por qualquer trabalhador. Dessa forma, as organizações que pretendem ter sucesso no desenvolvimento das suas atividades precisam de uma gestão mais participativa com seus colaboradores. E para que a organização tenha um eficiente nível de qualidade e produtividade sendo preciso reconhecer e investir em seus funcionários, como pessoas que precisam de motivação e capacitação no ambiente organizacional.

Alguns fatores são cruciais para a qualidade de vida nas organizações, tendo como uma dimensão de diversos fatores, Borges (2012) e Rodrigues (1999) dimensionaram sobre o tema. O Quadro 1 sintetiza suas concepções:

Quadro 1 - Resumo dos fatores que influenciam na qualidade de vida no trabalho

\begin{tabular}{|c|l|}
\hline \multirow{4}{*}{ Autores } & $\begin{array}{l}\text { Fatores que influenciam a qualidade de vida no } \\
\text { trabalho }\end{array}$ \\
\hline \multirow{4}{*}{$\begin{array}{c}\text { Borges } \\
(2012)\end{array}$} & - Saúde física e Psicológica \\
\cline { 2 - 3 } & - Hábitos Saudáveis \\
\cline { 2 - 3 } & - Tempo para lazer \\
\cline { 2 - 3 } & - Relações sociais e socioambientais \\
\hline \multirow{5}{*}{$\begin{array}{l}\text { Rodrigues } \\
\text { (1999) }\end{array}$} & $\begin{array}{l}\text { - Renda capaz de satisfazer as expectativas pessoais } \\
\text { e sociais }\end{array}$ \\
\cline { 2 - 3 } & - Orgulho pelo trabalho realizado \\
\cline { 2 - 3 } & - Vida emocional satisfatória \\
\cline { 2 - 3 } & - Autoestima \\
\cline { 2 - 3 } & - Bem-estar \\
\cline { 2 - 3 } & - Equilíbrio entre trabalho e lazer \\
\cline { 2 - 3 } & - Oportunidade e perspectiva de carreira \\
\cline { 2 - 3 } & - Justiça nas recompensas. \\
\hline
\end{tabular}
Fonte: Souza (2015).

Os fatores mencionados pelos autores, no quadro acima, afetam para a busca do bem-estar dos funcionários no ambiente das empresas. E, ainda, de acordo com os dois autores, a importância de se preservar e manter hábitos saudáveis gera e proporciona satisfação para cada trabalhador, no âmbito organizacional e pessoal. Antes da implantação de estratégias que motivem e estimulem um ambiente favorável para satisfação do colaborador, a empresa precisa avaliar a forma como é percebida a QVT pelos seus colaboradores, para então estipular métodos ou ferramentas que melhorem a relação da qualidade percebida pelos funcionários.

A relevância de se analisar o ambiente organizacional se torna um instrumento medidor de parâmetros concretos sobre a real situação que se encontra a qualidade de vida no ambiente de trabalho. Dessa forma, proporcionando uma investigação 
empírica baseada em métodos usados e debatidos por autores importantes sobre o assunto, em que é essencial para execução de melhorias e implantação de programas voltados para a QVT.

[...] o trabalho de Walton (1975) forneceu um modelo de análise de experimentos importantes sobre qualidade de vida no trabalho com oito categorias conceituais como critérios de QVT, incluindo: compensação justa e adequada, condições de trabalho seguras e saudáveis, oportunidades imediatas para desenvolver e usar as capacidades humanas, oportunidades futuras para o crescimento contínuo e a garantia de emprego, integração social na organização, constitucionalismo na organização, trabalho e espaço total na vida do indivíduo, e relevância social do trabalho (LIMONGI FRANÇA, 2004 p.34).

Tais fatores mencionados pela autora acima favorece para um clima organizacional agradável, dessa forma, melhora a qualidade e expectativa dos funcionários no ambiente da empresa. Analisar tais fatores na empresa é vital para gestão da QVT na organização, podendo apresentar ferramentas que auxiliem no desenvolvimento de melhoria no local de trabalho.

\subsection{Condições de trabalho seguras e saudáveis}

É importante estabelecer que o ambiente de trabalho é o lugar no qual as pessoas estão confinadas para exercer suas atividades laborais, e neste local precisa de no mínimo condições dignas para que o colaborador se sinta motivado e comprometido com o desenvolvimento de suas tarefas.

O meio ambiente de trabalho é, exatamente, o complexo máquinas e trabalho: as edificações do estabelecimento, equipamentos de proteção individual, iluminação, conforto térmico, instalações elétricas, condições de salubridade ou insalubridade, de periculosidade ou não, meios de prevenção à fadiga, outras medidas de proteção ao trabalhador, jornadas de trabalho e horas-extras, intervalos, descansos, férias, movimentação, armazenagem e manuseio de materiais que formam o conjunto de condições de trabalho etc. (NASCIMENTO, 2010, p.835).

Como pode se observar pela citação do autor acima, o conceito de meio ambiente de trabalho é amplo, envolvendo vários aspectos. Entre os quais vão desde a estrutura física aonde é exercido o trabalho, e outras medidas de proteção que engloba os direitos dos trabalhadores, formando um conjunto integrado de medidas que assegurem a segurança do funcionário no local de trabalho (BRITO, 2014).

Toda profissão tem sua regulamentação sobre os aspectos que envolvem o ambiente de trabalho. Nesse contexto, cabe aqui mencionar sobre as normas de saúde e segurança no trabalho que regem sobre o ambiente dos profissionais, que trabalham no setor de call center, estando previstas na norma regulamentadora do Ministério do Trabalho e Emprego - MTE, de $n^{\circ} 17$, Portaria $n^{\circ}$ 9, de 30 de março de 2007, anexo II, que trata de aspectos ergonômicos e condições ambientais, em que o operador necessita diariamente para o exercício das suas atividades, ou seja, mecanismos materiais ou treinamentos que o empregador, por lei, tem que oferecer aos profissionais que trabalham nesse ramo (REIS, 2010).

\subsection{O profissional do setor de call center}

De acordo com Amormino (2011), o termo call center surgiu em meados da década de 1990 e é formado pela junção de telecomunicações, computadores altamente equipados e marketing. No Brasil, os bancos foram os pioneiros em sua implementação, utilizando-se da figura de propulsor, logo mais tarde tornando esse tipo de serviço importante nos ambientes corporativos, que precisavam realizar tarefas do tipo cobranças, vendas e pesquisas de mercado.

O call center é uma central de atendimento telefônico que tem como principal responsabilidade ser o primeiro nível de relacionamento entre uma Empresa e seus clientes e/ou Fornecedores, portanto, é o elo da Empresa mais atuante neste sentido, sendo o elemento de importante relevância na manutenção, melhora ou piora da imagem e credibilidade da empresa (VASCONCELLOS, 2009, p.11).

É por meio do call center que, praticamente, a maioria das organizações de qualquer tamanho e tipo de mercado, podem obter melhorias consideráveis nos relacionamentos com seus clientes, seja nas prestações de serviços ou vendas de produtos (PEPPERS; ROGER, 2000).

Sabendo da importância que um departamento de call center ou central de comunicação tem para uma empresa, a gestão e a capacitação de profissionais que atuam nesse segmento, os chamados operadores de telemarketing ou agentes têm uma grande parcela de colaboração no desenvolvimento de atividades ligadas ao setor, sendo o principal profissional responsável para otimização dos serviços.

Para Quinteiro (1995), a atividade de teleoperador é uma profissão que exige muito da capacidade, tanto técnica como mental, do indivíduo, pelo fato de se trabalhar com ligação direta com cliente, requerendo atenção, simpatia, rapidez de raciocínio e muita paciência.

\subsection{Discussão dos dados coletados}

Para atingir o objetivo geral deste artigo foram coletados e analisados os dados sobre a percepção dos operadores de telemarketing de uma empresa de gestão de cobrança, sobre a qualidade de vida no ambiente organizacional em que se encontram. As questões se enquadram em oito categorias, baseadas no modelo de Walton (1975), que conceitua critérios para análise de qualidade de vida no trabalho.

Quanto à jornada de trabalho semanal, 60\% dos operadores se consideram satisfeitos em relação a sua jornada de trabalho e, $40 \%$ se consideram muito satisfeitos.

É evidente que todos estão satisfeitos em relação à jornada de trabalho que cumprem, em função da regulamentação, os operadores de telemarketing só podem trabalhar seis horas diárias ou 36 horas semanais. Na empresa pesquisada, as atividades diárias são divididas em dois turnos de trabalho, 
um pela manhã e outro pela tarde.

Com relação às condições ambientais do local de trabalho, $50 \%$ dos trabalhadores responderam que estão satisfeitos, $40 \%$ muito satisfeitos e $10 \%$ muito insatisfeitos. As respostas evidenciadas são preocupantes, visto que apesar de $90 \%$ dos entrevistados estarem satisfeitos, $10 \%$ dos respondentes se sentem muito insatisfeitos. Aspectos como iluminação, higiene, ventilação, organização, equipamentos, móveis e outros são levados em consideração para um ambiente favorável e propício para o exercício de suas atividades. Já que os $10 \%$ não estão nada satisfeitos, cabe verificar em qual aspecto a empresa pesquisada precisa melhorar, no entanto é evidente que a empresa preza por um ambiente adequado para os profissionais atuantes no call center, mas não se pode desconsiderar a insatisfação de alguns operadores.

Quanto à adequação do salário em relação ao trabalho desempenhado (Figura 1), a metade dos entrevistados, ou seja, 50\% acham a remuneração parcialmente adequada, considerando-se apenas satisfeitos, sendo que 30\% dos respondentes concordam integralmente com a remuneração percebida, ou seja, estão muito satisfeitos e, os demais $20 \%$ indeferem nem satisfeito e nem insatisfeito.

Figura 1 - Como se sente em relação à adequação do seu salário ao trabalho

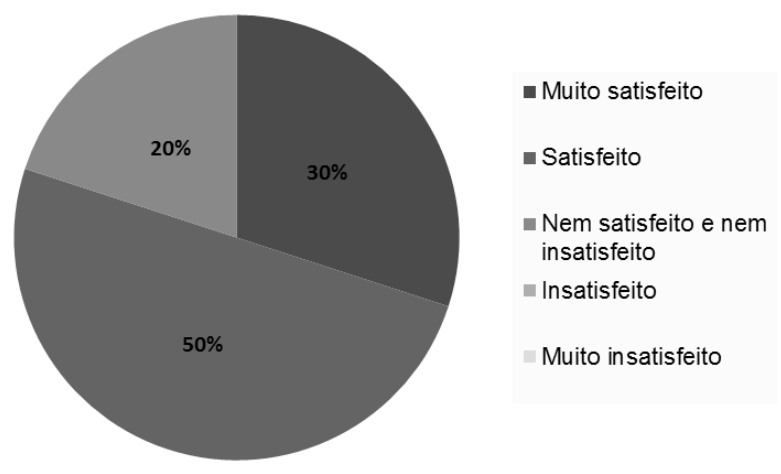

Fonte: dados da pesquisa.

Apesar de haver $20 \%$ de pesquisados respondendo, de forma indiferente, isso não dá margem para dúvida de que os operadores estão contentes com o salário que recebem. Para Fernandes (1996), a remuneração adequada é aquela necessária para o trabalhador viver dignamente dentro das necessidades pessoais e dos padrões culturais, sociais e econômicos da sociedade em que vive.

Quanto ao grau de satisfação do pesquisado em relação à avaliação de desempenho (Figura 2), 70\% dos operadores se manifestaram satisfeitos em relação à avaliação de desempenho aplicado por seus superiores, com fins de obtenção dos índices de eficiência e eficácia, avaliando o desempenho no exercício das suas atividades, ou seja, o feedback que a empresa fornece. Do total de respondentes, $20 \%$ indeferem, respondendo de forma indiferente e, $10 \%$ se consideram muito satisfeito.
Figura 2 - Expõe o grau de satisfação do pesquisado em relação à avaliação de desempenho

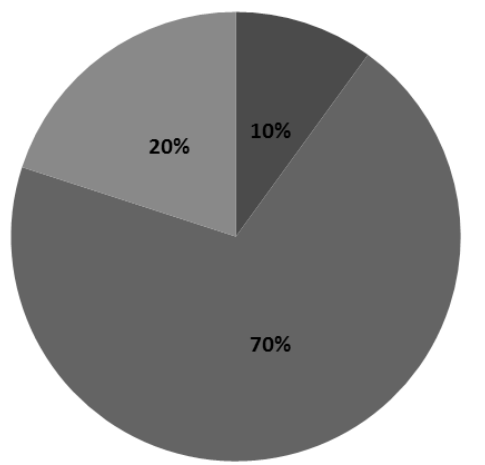

- Muito satisfeito

- Satisfeito

Nem satisfeito e nem insatisfeito

- Insatisfeito

Muito insatisfeito

Fonte: dados da pesquisa.

Percebe-se que $80 \%$ dos entrevistados estão contentes com o feedback recebido. Para Davis e Newstron (2001, p. 65): "o feedback pelo desempenho tende a encorajar uma melhor performance e gera uma realimentação que representa um instrumento motivacional especialmente poderoso".

Quanto à responsabilidade que é dada para cada operador e como esse se sente acerca de seu trabalho $60 \%$ dos entrevistados responderam que se sentem satisfeitos, 30\% muito satisfeitos e apenas $10 \%$ se sentem insatisfeitos.

Considera-se um ponto importante em se avaliar, verificando se o operador está motivado e comprometido com as tarefas que são lhe impostas, tendo $90 \%$ dos operadores respondendo, positivamente, o que demostra que a maioria se sente confortável com seu dever diário, e apenas uma pequena minoria que precisa ser monitorada, pois ainda se sentem insatisfeitos com suas atribuições.

Com relação à oportunidade de crescimento profissional que empresa oferece (Figura 3), 40\% dos operadores estão satisfeitos, já outros $30 \%$ estão muito satisfeitos, sendo que $20 \%$ indeferem, respondendo de forma indiferente e, 10\% se consideram totalmente insatisfeitos.

Figura 3 - Estampa o grau de satisfação em relação à oportunidade de crescimento profissional.

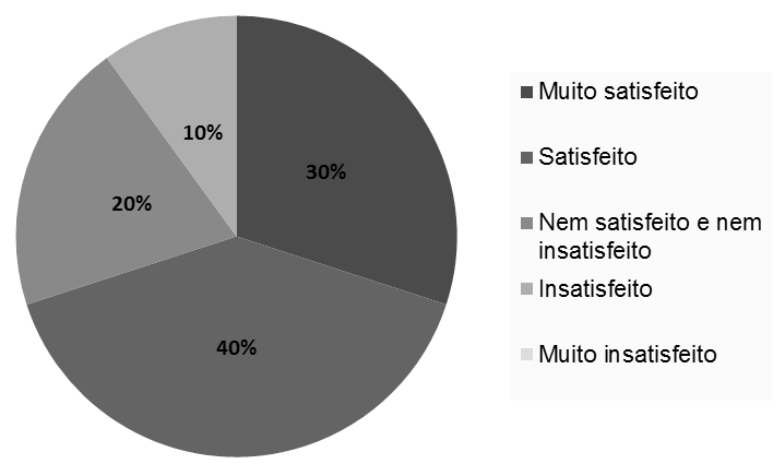

Fonte: dados da pesquisa.

A oportunidade de crescimento e segurança são as políticas da instituição no que concerne ao desenvolvimento, ao crescimento e segurança de seus colaboradores, ou seja, a possibilidade de carreira, crescimento pessoal e segurança no emprego (VASCONCELOS, 2001). É visto que a empresa 
procura investir em crescimento pessoal e profissional de seus colaboradores, para melhor alocar pessoas, visto que cabe ainda dinamizar políticas de plano de cargos e salários para todos, pois não se pode desconsiderar um número alto $(30 \%)$ de colaboradores indiferente ou insatisfeitos.

No aspecto integração organizacional em que se avalia a convivência no ambiente de trabalho com os colegas, o relacionamento e senso comunitário que são compartilhados, $50 \%$ dos operadores responderam que se sentem satisfeitos e $40 \%$ muito satisfeitos, outros $10 \%$ indeferem sobre o assunto,

Haja vista os resultados, fica claro que o clima organizacional da empresa é agradável. Observa-se que "clima organizacional" difere de "ambiente organizacional", em que $10 \%$ dos pesquisados responderam estarem totalmente insatisfeitos. De acordo com Vasconcelos (2001), em integração social na organização se pode, efetivamente, observar se há igualdade de oportunidade, independente da orientação sexual, classe social, idade, e outras formas de discriminação, bem como se cultiva o bom relacionamento.

Com relação ao envolvimento de todos os colaboradores no processo e desenvolvimento das atividades no setor de call center, em relação ao comprometimento da equipe, $70 \%$ dos operadores avaliaram e responderam que se sentem satisfeitos e outros 30\% muito satisfeitos.

Essa é uma questão muito interessante, já que 100\% dos operadores estão comprometidos com as relações harmoniosas e de resultados positivos para com a empresa.

Quando questionados como se sentem em relação à liberdade de expressão na empresa que é a capacidade de opinar e trazer ideias ou críticas para a organização, 50\% dos pesquisados responderam que se sentem confortáveis com esse aspecto e $40 \%$ responderam que estão muito satisfeitos, contra apenas $10 \%$ com opinião indiferente.

Aqui cabe um comentário importante. Se em vários pontos abordados anteriormente a maioria respondeu que, em geral estão satisfeitos, por que há esse número de pesquisados respondendo que não estão satisfeitos com o grau de liberdade de expressão e com as condições ambientais do local de trabalho, dentro da organização? Fica a pergunta. No entanto, surge um parâmetro para uma nova pesquisa com questionários abertos ou entrevistas, o que avaliaria de forma mais precisa quais questões estão trazendo pontos negativos.

O constitucionalismo deve ser respeitado para propiciar criatividade, serenidade, responsabilidade e capacidade de demonstrar ou desenvolver novas habilidades, resultando, assim, em melhor retorno para a própria empresa (FERNANDES; CORONADO, 2008).

Quanto à influência das atividades do trabalho na vida familiar e pessoal dos operadores a maioria dos entrevistados, $50 \%$ se sentem satisfeitos em relação ao tempo disponível que têm, outros $40 \%$ se sentem muito satisfeitos e apenas $10 \%$ se sentem insatisfeitos.

Foi questionado como se sentem em relação ao tempo disponível que possuem fora do ambiente de trabalho, seja para lazer ou atividades sociais que cada um tem para se entreter. A própria empresa pesquisada patrocina eventos de corridas e incentiva todos seus colaboradores a participarem como forma de lazer e bem-estar.

Em relação a como os operadores se sentem com as pausas e horários do turno em que trabalham, a maioria dos pesquisados, $50 \%$ se sentem satisfeitos, e outros $40 \%$ muito satisfeitos e apenas $10 \%$ insatisfeitos.

Conforme mencionado, os operadores fazem uma jornada de 6 horas diárias, e por direito necessitam ter pausas com intervalos para descanso, para prevenir sobrecarga psíquica, muscular estática de pescoço, dorsos e membros superiores por causa da sua atividade.

Cabe aqui mencionar que a empresa pode estar realizando questionamentos no momento do feedback, se os operadores estão satisfeitos com os horários em que trabalham e qual seria o mais ideal, assim adequando os melhores horários para cada operador, reduzindo esse percentual de $10 \%$ insatisfeitos em relação ao horário a que trabalham e suas pausas para descanso.

Com relação à prática de gestão de pessoas adotadas pela empresa, $70 \%$ dos pesquisados consideram satisfatória e 30\% muito satisfatória.

Fica claro que os operadores estão contentes com a política de gestão adotada pela empresa, demonstrando uma grande aprovação por parte de todos os entrevistados. Isso demonstra que a empresa está fazendo a sua parte, buscando a satisfação de seus colaboradores.

Quanto à visão que os operadores têm sobre a qualidade de vida total no ambiente em que trabalham e que abrange todas as questões mencionadas nesta pesquisa, 50\% afirmam estarem satisfeitos e $50 \%$ muito satisfeitos.

A resposta a esta questão demonstra, mais uma vez, que a empresa está no caminho certo, envidando esforços para que o seu colaborador se sinta satisfeito. É evidente que a organização em que foi realizada a pesquisa se preocupa com aspectos relacionados com a qualidade de vida dos seus colaboradores, o que indica em baixa rotatividade de operadores na empresa.

\section{Conclusão}

As organizações atuais estão preocupadas em oferecer qualidade na entrega de seus produtos e serviços, em um mercado cada vez mais competitivo, dessa maneira, precisam investir em seu maior patrimônio, o capital humano, que é o elo mais importante para se chegar aos seus objetivos. Visando isso, o processo de implantação de programas de qualidade de vida no trabalho proporciona melhores condições e satisfação para todos os colaboradores.

Portanto se chegou à conclusão de que a maioria dos operadores da empresa pesquisada se sentem satisfeitos com os aspectos relacionados à qualidade de vida no ambiente de trabalho, no setor de call center, trazendo atenção para alguns pontos que o empregador precisa avaliar, que são de 
oportunidade de crescimento profissional, na qual alguns estão insatisfeitos ou indeferem sobre o assunto, o que precisa ser mais esclarecido e difundido para todos os colaboradores, podendo rever as práticas de gestão de cargos e salários, que mais se adequam à categoria do profissional, trazendo políticas de benefícios como um atrativo motivacional.

Outro ponto importante que cabe ressaltar é sobre as condições do ambiente de trabalho dos operadores. Se há um número pequeno que se considera insatisfeito em relação às condições ambientais na empresa, compete à organização verificar quais aspectos estão deixando a desejar no conforto e segurança dos operadores, e que acabam afetando na produtividade desses.

Dessa forma, a pesquisa guarda sua relevância, pois trouxe consideráveis resultados do aspecto e percepção que os funcionários da empresa têm sobre variados fatores, que formam a qualidade de vida no trabalho e proporcionam melhores condições ambientais, psicológicas e sociais para os operadores. Assim, apresentando questões que são cruciais para que a organização verifique o que precisa ser aprimorado e discutido, para desenvolver, difundir, e motivar seus funcionários, para criação de valor de todos envolvidos no processo de prestação de serviço.

\section{Referências}

AMORMINO, S. A. Qualidade de vida trabalho dos operadores de telemarketing em call center: um estudo de caso em um laboratório de análises clínicas. 2011. 121 f. Dissertação (Mestrado) - Curso de Mestrado em Administração, Fundação Pedro Leopoldo, Pedro Leopoldo, 2011.

BORGES, U.N. Benefícios da ginástica laboral na qualidade de vida no trabalho: um estudo de caso numa empresa produtora de cadernos. 2012. 107f. Dissertação (Mestrado em Engenharia de Produção) - Programa de Pós-graduação em Engenharia de Produção, João Pessoa. 2012.

BARRETOS, A.C.R.S. Estresse conheça este inimigo. 2008 Disponível em: <http:www.saude.com.br>. Acesso em: 5 maio 2020.

BRITO, V.A.S. O direito do empregado ao ambiente de trabalho seguro e saudável: a tutela do princípio da dignidade humana. Rev. Jus Navigandi, p.1-19, 2014. Disponível em: <https://jus. com.br/artigos/31440/o-direito-do- empregado-ao-ambiente-detrabalho seguro-e-saudável>. Acesso em: 13 maio 2020.

CHIAVENATO, I. Gestão de pessoas. Rio de Janeiro: Elsevier, 2004.

DAVIS, K; NEWSTRON, J. Comportamento humano no trabalho: uma abordagem organizacional. São Paulo: Pioneira Thompson Learning, 2001.

FERNANDES, E.C. Qualidade de vida no trabalho: como medir para melhorar. Salvador: Casa da Qualidade, 1996.

FERNANDES, C.A.; CORONADO, A.B. Qualidade de vida no trabalho: fator decisivo no desempenho organizacional. 2008. Disponível em: <http:// http://www.administradores.com.br/ artigos/economia-e-financas/qualidade-de-vida- no-trabalhofator-decisivo-no-desempenho-organizacional/26723/>. Acesso em: 14 junho. 2020.

GIL, A.C. Métodos e técnicas de pesquisa social. São Paulo: Atlas, 2008.

LIMONGI-FRANÇA, A.C. Qualidade de vida no trabalho-QVT: conceitos e práticas nas empresas da sociedade pós-industrial. São Paulo: Atlas, 2004.

MARTINS, M.M. Qualidade de vida e capacidade para o trabalho dos profissionais em enfermagem no trabalho em turnos. Florianópolis: UFSC, 2002.

NASCIMENTO, A.M. Curso de Direito do Trabalho: história e teoria geral do direito do trabalho: relações individuais e coletivas do trabalho. São Paulo: Saraiva, 2010.

NASCIMENTO, N.M.S. Qualidade de vida nas organizações. Rio de Janeiro: Universidade Candido Mendes Avm, 2016.

PEPPERS; ROGER, G. CRM Series Marketing 1 to 1: um guia executivo para entender e implantar estratégias de customer relationship management. São Paulo: Pepper and Rogers Group do Brasil, 2000.

QUINTEIRO, E.A. O poder da voz e da fala no telemarketing. São Paulo. Summus, 1995, p. 77.

REIS, R. S. Segurança e medicina do trabalho: normas regulamentadoras. São Caetano do Sul: Yendis, 2010.

RIBEIRO, L.A; SANTANA, L.C. Qualidade de vida no trabalho: fator decisivo para o sucesso organizacional. Rev. Inic. Cient., V.2, n.2, p.75-96, 2015.

RICHARDSON, R.J. Pesquisa social: métodos e técnicas. São Paulo: Atlas, 2011.

ROCHA, V.M.; FERNANDES, M.H. Qualidade de vida de professores do ensino fundamental: uma perspectiva para a promoção da saúde do trabalhador. J. Bras. Psiquiatr., v.57, n.1, p.23-27, 2007.

RODRIGUES, M.V.C. Qualidade de vida no trabalho: evolução e análise no nível gerencial. Petrópolis: Vozes, 1999.

SOUZA, R.M. Qualidade de Vida no Trabalho (QVT): um estudo nos programas de pós-graduação do centro tecnológico de uma instituição de ensino superior. Florianopolis: Universidade Federal de Santa Catarina, 2015.

SANT'ANNA, A.S.; KILIMNIK, Z.M.; MORAES, L.F. Antecedentes, origens e evolução do movimento em torno da qualidade de vida no trabalho. Qualidade de vida no trabalho: abordagens e fundamentos. Rio de Janeiro: Elsevier, 2011.

VASCONCELLOS, L.R. Qualidade de atendimento em call center. Rio de Janeiro: Centro II, Universidade Candido Mendes, 2009.

VASCONCELOS, A.F. Qualidade de vida no trabalho: origem, evolução e perspectivas. 2001. Disponível em: <http://www. luzimarteixeira.com.br/wp- content/uploads/2009/06/qualidadede-vida-no-trabalho-origem.pdf $>$. Acesso em: 13 jun. 2020.

WALTON, R.E. Quality of working life: what is it? Sloan Management Rev., v.15, n.1, p.11-21, 1975.

YIN, R. K. Estudo de caso: planejamento e métodos. Porto Alegre: Bookmann, 2001. 